\title{
Evidence to Support Development of Pharmacy Services: How Much or How Little Do We Need?
}

\author{
Scot H Simpson
}

$\mathrm{W}$ are all challenged by limited resources of time, personnel, and funding in our various practice settings. Yet despite these limitations, there are many demands and expectations to develop and expand pharmacy services. These demands come from various sources, including accreditation standards such as the Required Organizational Practices of Accreditation Canada, ${ }^{1}$ colleagues within our facilities, our own clinical practice interests, and elsewhere. Ideally, the premise for a new or expanded pharmacy service will be incontrovertible evidence from randomized controlled trials demonstrating benefit in terms of clinical outcomes and sound economic evidence demonstrating that the maximum benefit is being generated from the resources consumed. ${ }^{2}$ However, we often do not have the luxury of these high levels of evidence, which raises the following question: When do we have enough evidence to support the development of a new pharmacy service?

There are 2 extreme and opposing perspectives about the necessity of robust evidence from clinical trials to help guide decision-making. The first is that we should implement only those programs that have evidence from randomized controlled trials demonstrating significant improvements in clinical outcomes. With this perspective in mind, I am reminded of a systematic review conducted by Smith and Pell. ${ }^{3}$ Although these authors wanted to determine if parachutes were effective in preventing major adverse outcomes after "gravitational challenge" by summarizing the evidence from randomized controlled trials, an extensive literature search yielded no such trials. Even in the absence of this "gold standard" level of evidence, however, many of us have jumped from an airplane or other structure and have trusted that a parachute would significantly reduce the risk of an adverse outcome.

The second and opposing perspective is to adopt good ideas with little or no evidence except that "it just makes sense". In my pharmacoepidemiology course, I use examples from the Cardiac Arrhythmia Suppression Trial (CAST), ${ }^{4}$ the
Heart Outcomes Prevention Evaluation (HOPE) study, ${ }^{5}$ and the Diabetes Reduction Assessment with Ramipril and Rosiglitazone Medication (DREAM) study ${ }^{6}$ to illustrate the need for care in our pursuit of an idea that sounds good. In both of these examples-pharmacologic suppression of

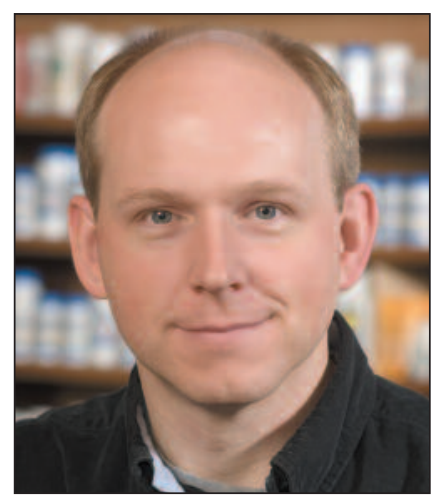
abnormal ventricular rhythms after myocardial infarction (CAST) and use of angiotensin-converting enzyme inhibitors to prevent diabetes (the HOPE and DREAM studies)clinicians were willing to adopt the pharmacologic theories until randomized controlled trials demonstrated that these ideas were fatal or ineffective, respectively.

Obviously, there is a moderate approach between these 2 extremes, where we should use the strongest, most relevant evidence from randomized controlled trials, quasi-experimental studies, or observational studies to help inform the decision to implement a new pharmacy service.

In this issue of the CJHP, 2 groups of pharmacists describe their approaches to the development of new clinical pharmacy services. Bussières and colleagues ${ }^{7}$ describe their development of a pharmaceutical care program in a pediatric hematologyoncology service. Mysak and colleagues ${ }^{8}$ describe how they restructured their institution's clinical pharmacy services and the impact that this restructuring had on stakeholder satisfaction. Some important similarities between these 2 projects highlight the need for a systematic, evidence-based approach when implementing a new pharmacy service. Both groups began their projects with a review of current practice to identify important gaps or needs in their respective institutions. Each of these assessments was coupled with a 
literature review to identify the best available evidence. Bussières and colleagues aimed to identify controlled trials and other evidence to support clinical pharmacy activities within a hematology-oncology service. ${ }^{7}$ Mysak and colleagues combined their literature search with a consensus meeting of their clinical practice leaders to identify a core set of proactive clinical pharmacy services. ${ }^{8}$ The next important step that both groups took was to gather feedback from stakeholders before implementing their interventions. The final step reported in both papers was an assessment of the impact of the new pharmacy service in each institution.

The methods used by both groups to develop and evaluate their programs are consistent with a quality improvement process described by various organizations. ${ }^{9,10}$ Briefly, this process involves 6 steps: (1) identify priority areas, (2) identify best practices or a benchmark from the literature, (3) examine current practice patterns to determine where important gaps exist, (4) hold discussions with stakeholders to develop an intervention aimed at improving current practice, (5) implement the intervention, and (6) evaluate the program to determine if clinical, economic, or humanistic outcomes have improved. . $^{911}$ The decision to initiate or expand a pharmacy service is certainly difficult when time, personnel, and financial resources are limited. The initiatives by Bussières and colleagues ${ }^{7}$ and Mysak and colleagues ${ }^{8}$ serve as examples of how we can use an evidence-based approach when developing clinical pharmacy services. Judicious use of the strongest, most relevant evidence to support these decisions will help us to implement pharmacy services that will have important benefits for patients, our facilities, and our staff.

\footnotetext{
References

1. Required organizational practices. Ottawa $(\mathrm{ON})$ : Accreditation Canada [cited 2010 Jan 15]. Available from: www.accreditation.ca/accreditationprograms/qmentum/required-organizational-practices/

2. Detsky AS, Naglie IG. A clinician's guide to cost-effectiveness analysis. Ann Intern Med 1990;113(2):147-154.
}

3. Smith GC, Pell JP. Parachute use to prevent death and major trauma related to gravitational challenge: systematic review of randomised controlled trials. BMJ 2003;327(7429):1459-1461.

4. Echt DS, Liebson PR, Mitchell LB, Peters RW, Obias-Manno D, Barker $\mathrm{AH}$, et al. Mortality and morbidity in patients receiving encainide, flecainide, or placebo. The Cardiac Arrhythmia Suppression Trial. N Engl J Med 1991;324(12):781-788

5. Yusuf S, Sleight P, Pogue J, Bosch J, Davies R, Dagenais G. Effects of an angiotensin-converting-enzyme inhibitor, ramipril, on cardiovascular events in high-risk patients. The Heart Outcomes Prevention Evaluation Study Investigators. N Engl J Med 2000;342(3):145-153.

6. Bosch J, Yusuf S, Gerstein HC, Pogue J, Sheridan P, Dagenais G, et al. Effect of ramipril on the incidence of diabetes. $N$ Engl J Med 2006; 355(15):1551-1562.

7. Bussières JF, Robelet A, Therrien R, Touzin K. Démarche pour la mise à niveau d'un secteur de soins pharmaceutiques : le cas de l'hémato-oncologie pédiatrique. Can J Hosp Pharm 2010;63(2):119-129.

8. Mysak T, Rodrigue C, Xu J. Care providers' satisfaction with restructured clinical pharmacy services in a tertiary care teaching hospital. Can J Hosp Pharm 2010;63(2):105-112.

9. McQueen L, Mittman BS, Demakis JG. Overview of the Veterans Health Administration (VHA) Quality Enhancement Research Initiative (QUERI). J Am Med Inform Assoc 2004;11(5):339-343.

10. King KM, Bungard TJ, McAlister FA, Ackman ML, Simpson SH, Teo $\mathrm{KK}$, et al. Quality improvement for CQI. Prev Med Manag Care 2000;1(3):129-137.

11. Kozma CM, Reeder CE, Schulz RM. Economic, clinical, and humanistic outcomes: a planning model for pharmacoeconomic research. Clin Ther 1993;15(6):1121-1132.

Scot H Simpson, BSP, PharmD, MSc, is an Associate Professor with the Faculty of Pharmacy and Pharmaceutical Sciences, University of Alberta, Edmonton, Alberta, and is supported as a New Investigator by the Canadian Institutes of Health Research. He is also an Associate Editor for the CJHP.

Address correspondence to:

Dr Scot H Simpson

Faculty of Pharmacy and Pharmaceutical Sciences

2125A Dentistry/Pharmacy Centre

University of Alberta

Edmonton AB T6G 2N8

e-mail: ssimpson@pharmacy.ualberta.ca

\section{ON THE FRONT COVER}

\section{Mount Robson, British Columbia}

This photograph was taken on the afternoon of October 10, 2009, at Mount Robson Provincial Park near Valemount, British Columbia. The photographer was pharmacist and CSHP member Arden Barry, a student in the PharmD program at the University of British Columbia. At the time the photograph was taken, he

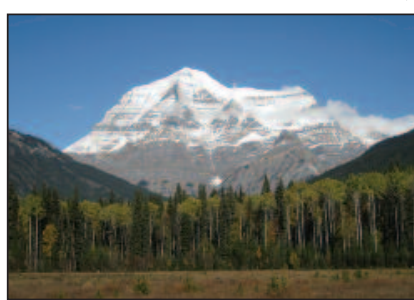

had just completed a clinical PharmD rotation in Edmonton and was driving to Vancouver to start another rotation. The image, obtained with a Canon Powershot SD600 digital camera, depicts the southern face of Mount Robson, which is visible from the Yellowhead Highway.

The CJHP would be pleased to consider photographs featuring Canadian scenery taken by CSHP members for use on the front cover of the journal. If you would like to submit a photograph, please send an electronic copy (minimum resolution $300 \mathrm{dpi}$ ) to Sonya Long at slong@cshp.ca. 